\title{
A Schematic Overview of the Current Status of Male Infertility Practice
}

\author{
Ashok Agarwal $^{1,2(1)}$, Ahmad Majzoub ${ }^{1,3(1)}$, Neel Parekh ${ }^{2}$ (i) , Ralf Henkel $^{1,4(1)}$ \\ ${ }^{1}$ American Center for Reproductive Medicine, Cleveland Clinic, ${ }^{2}$ Department of Urology, Cleveland Clinic, Cleveland, OH, USA, \\ ${ }^{3}$ Department of Urology, Hamad Medical Corporation and Weill Cornell Medicine-Qatar, Doha, Qatar, ${ }^{4}$ Department of Medical Bioscience, \\ University of the Western Cape, Cape Town, South Africa
}

\begin{abstract}
The practice of male infertility has dramatically evolved over the past few decades. This has been achieved after the realization of the important contribution the male counterpart holds in the couple's infertility. It is also supported by a number of breakthroughs in the diagnosis and treatment of this medical condition. Several tests to investigate sperm quality and function were introduced along with refinements and/or institution of novel surgical techniques that can correct several causes of infertility. This manuscript is aimed at highlighting the current state of male infertility practice in a robust, schematic method addressing a broader audience involved in the treatment of male infertility.
\end{abstract}

Keywords: Andrology; Hormones; Infertility, male; Oxidative stress; Semen analysis

This is an Open Access article distributed under the terms of the Creative Commons Attribution Non-Commercial License (http://creativecommons.org/licenses/by-nc/4.0) which permits unrestricted non-commercial use, distribution, and reproduction in any medium, provided the original work is properly cited.

\section{INTRODUCTION}

After the birth of Louise Brown in 1978, the first successful delivery from an in vitro fertilization procedure [1], the fields of human reproduction and embryology have witnessed major breakthroughs that allowed couples previously regarded as sterile to conceive their own biologic children. This was made possible through the enhanced understanding of the physiology of fertilization and pathophysiology of infertility allowing a cause-directed treatment approach to a variety of etiologies. Subsequent advances in assisted reproductive technologies (ART) have revolutionized our comprehension of the sperm/egg interaction at the molecular level.
In recent years, a plethora of research was conducted on the study of male infertility, primarily as a result of the perceived decline in semen quality among healthy men worldwide, the growing public awareness and the psychological impact of this condition on men's health and wellbeing. Advances in diagnostic and treatment modalities of the infertile man have emerged, including testing of sperm function, genomic and proteomic expression of seminal plasma proteins and refinement of microsurgical reconstructive surgeries. Training programs were developed worldwide to aid in the diagnosis and treatment of male reproductive conditions, allowing for the delivery of subspecialized care to this group of patients. Unfortunately, access to male infertility providers is highly variable both within the

Received: Apr 26, 2019 Revised: May 31, 2019 Accepted: Jun 9, 2019 Published online Jul 19, 2019

Correspondence to: Ashok Agarwal (iD https://orcid.org/0000-0003-0585-1026

American Center for Reproductive Medicine, Cleveland Clinic, Mail Code X-11, 10681 Carnegie Avenue, Cleveland, OH 44195, USA.

Tel: +1-216-444-9485, Fax: +1-216-445-6049, E-mail: agarwaa@ccf.org 
United States and around the globe. Several studies have highlighted this growing issue. For example, as of 2010, 1.5 million adults in Kentucky had access to a single infertility treatment center in the state. However, in the District of Columbia, there is one infertility treatment center for every 65,000 adults [2,3]. Nangia et al [2] further demonstrated this unequal distribution of male infertility providers across the United States [4]. As of 2010, there were only 197 male infertility specialists in the United States [2]. Moreover, 13 states had no male infertility provider and many more infertility treatment centers could not refer men to a male infertility specialist within a one hour driving distance. This disparity has required general urologists, who may not have had the training or harbor any interest in the subject, managing men with male factor infertility. This may potentially result in inadequate treatment of the male or unnecessarily proceeding with ART with its associated risks to the female partner.

In the United Kingdom, only 3.6\% of urology residents cited exposure to training in male factor infertility. While the majority of residents reported a desire to treat male factor infertility in their future practice, only $27 \%$ felt prepared to do so [5]. In the United States, the number of clinical andrology fellowships has been steadily growing, improving resident exposure. However, the Accreditation Council of Graduate Medical Education does not require learning procedural skills or core competencies in order to manage patients with male factor infertility [6]. Therefore, the disparity in access to fellowship trained male fertility specialists is likely to continue to grow.

Clearly, there is a need for a more comprehensive approach and lessening of the gap of care between patients and fertility specialists. Globally, male infertility management is shared with gynecologists, endocrinologists, dermatologists, internists and embryologists, especially in the setting of assisted reproduction (Fig. 1). This fact justifies the writing of manuscripts such as this one, which is aimed at highlighting the current state of male infertility practice in a simplified, easy to follow schematic method addressing a broader audience involved in the treatment of male infertility. This article will (1) review the key principles of male fertility evaluation; (2) explore important diagnostic tests involved in the work-up; and (3) elaborate on several treatments utilized in a number of presentations.

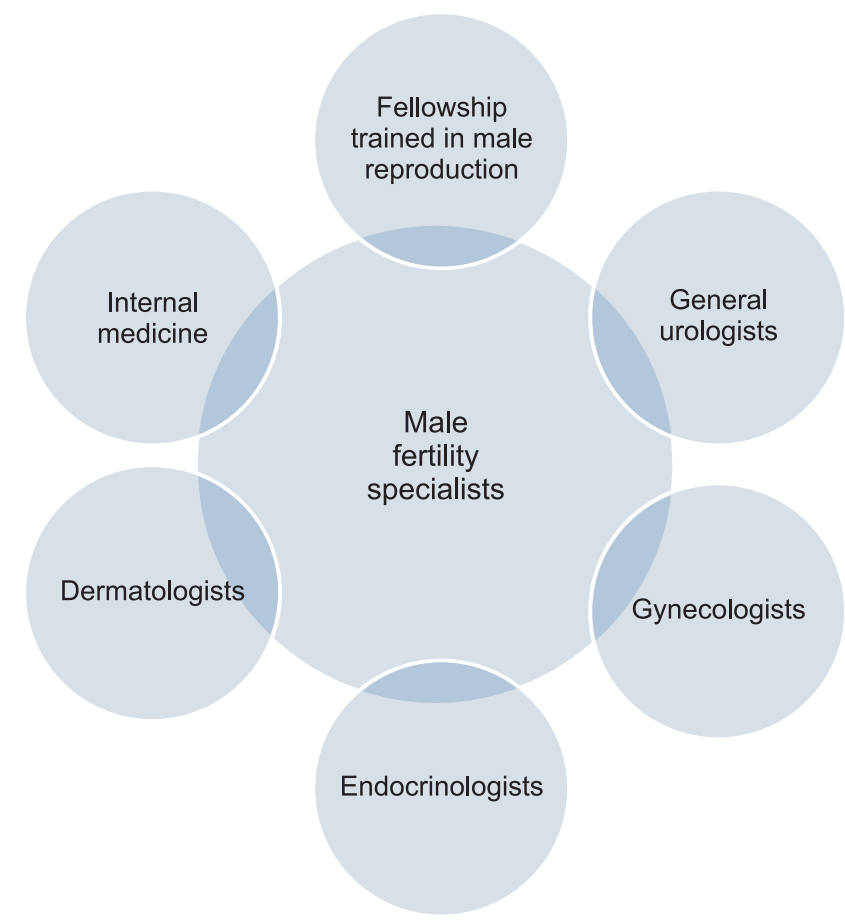

Fig. 1. Various male infertility specialists globally.

\section{MALE INFERTILITY: GENERAL CONSIDERATIONS AND THE INITIAL ASSESSMENT}

Infertility is defined as the inability of a couple to conceive after at least one year of regular unprotected intercourse. This condition has become a global health concern affecting about 187 million couples worldwide or one out of every six couples of reproductive age [7,8]. Among other complications, male infertility can lead to psychological problems, ridicule or domestic violence [9]. Particularly, in male driven societies, it can even force the female partner into extramarital relationships and thereby increase the risk of contracting sexually transmitted diseases, such as human immunodeficiency virus/acquired immune deficiency syndrome [10]. Since the male is partially or completely responsible for half the cases of infertility (Fig. 2) among couples, this underscores the importance of delivering a specialized male fertility evaluation for those seeking fertility [11].

The American Urological Association (AUA) and American Society of Reproductive Medicine (ASRM) recommends that at a minimum, the infertility workup includes a detailed history, physical exam and two separate semen analyses to identify risk factors for male infertility (Fig. 3, 4) [12,13]. Moreover, numerous causes of male infertility have been recognized and are 


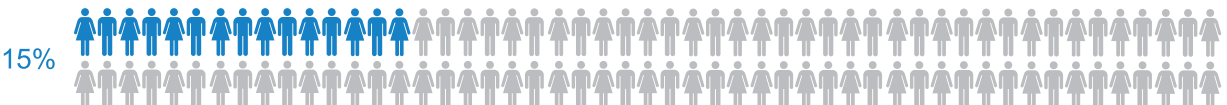

$1 / 7$ 인

Female factors

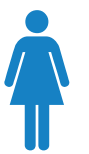

$50 \%$

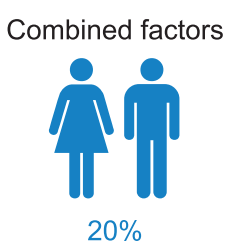

$20 \%$

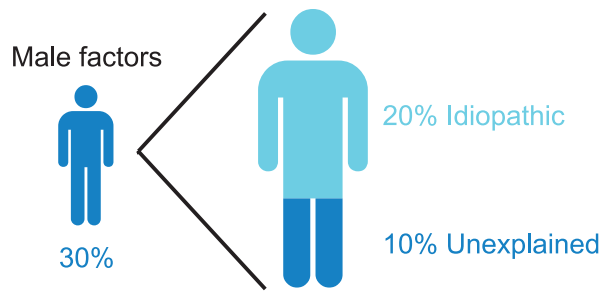

Fig. 2. Incidence of infertility.

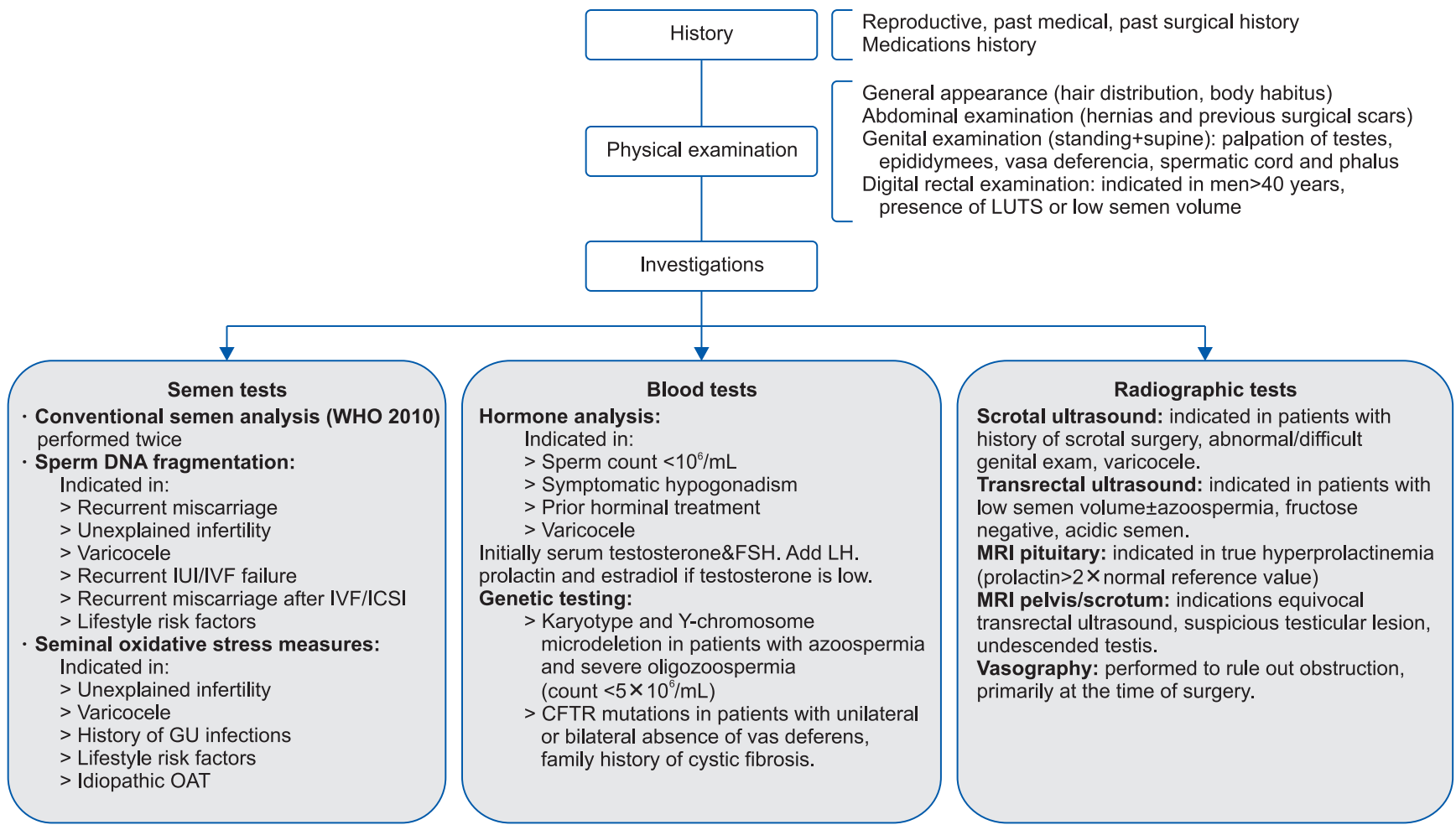

Fig. 3. Evaluation of male infertility. LUTS: lower urinary tract symptoms; WHO: World Health Organization, IUI: intrauterine insemination, IVF: in vitro fertilization, ICSI: intracytoplasmic sperm injection, GU: genitourinary, OAT: oligo-astheno-teratozoospermia, FSH: follicle-stimulating hormone, LH: luteinizing hormone, CFTR: cystic fibrosis transmembrane conductance regulator, MRI: magnetic resonance imaging.

classified at pre-testicular, testicular, or post-testicular (Fig. 5). The vast majority of these causes can be recognized with great certainty provided that a proper assessment has been conducted. Specific details regarding the couple's sexual activities are important to identify modifiable causes of delayed conception, such as timing and frequency of intercourse, ejaculation practices and/or lubricant use and presence of male sexual dysfunction. A checklist of risk factors should be directly solicited from patients including medical conditions, such as history of genitourinary infections, trauma or prior surgery; medication history, specifically the use of exogenous testosterone and chemotherapeutic medications; and environmental and lifestyle risk factors that are known to negatively impact fertility. These include smoking [14], obesity [15], alcoholism [16], exposure to heavy metals (lead, cadmium) [17], ionizing radiation [18], and high temperatures [19]. Furthermore, in roughly $1 \%$ of men who present for male fertility evaluation, a comprehensive evaluation has the ability 
to uncover more serious or potentially life-threatening conditions. Normal semen parameters and reproductive history should not preclude men from being fully assessed, approximately $0.16 \%$ of men can still harbor a significant medical condition [20].

The next step is a focused physical examination. The patients' general appearance can partly foreshadow their endocrine status, for example, hypogonadism may be suspected in patients with reduced facial hair, gynecomastia and obesity. Genital examination is performed in both the standing and supine positions. The testes, epididymides, vasa deferentia and the spermatic cord are individually palpated looking for abnormalities. The size and consistency of the testes can roughly estimate its spermatogenic function. Care must be taken to look for testicular masses as infertile men are 3 times more prone to develop testicular cancer [21].

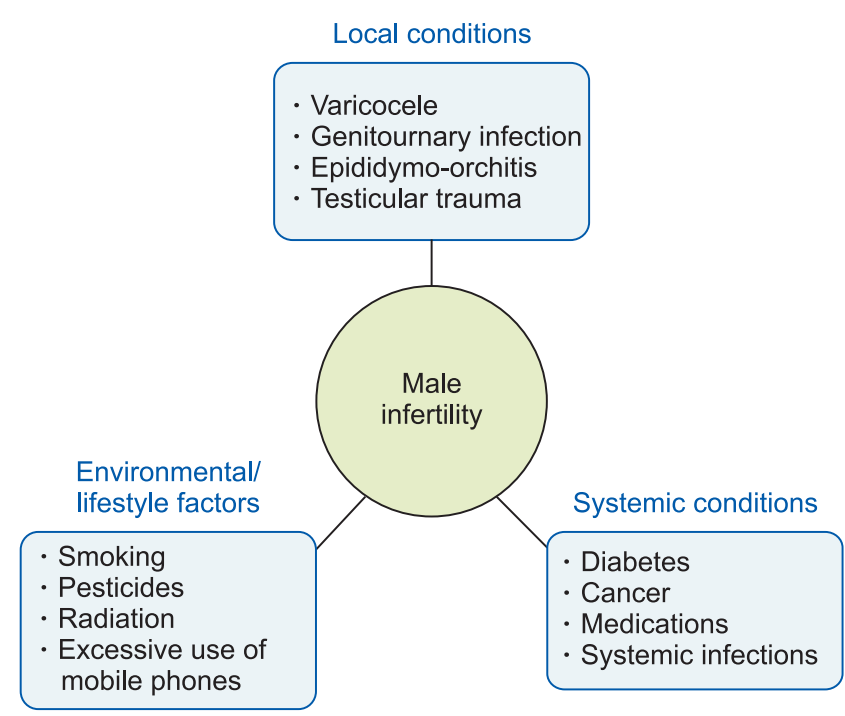

Fig. 4. Risk factors of male factor infertility.

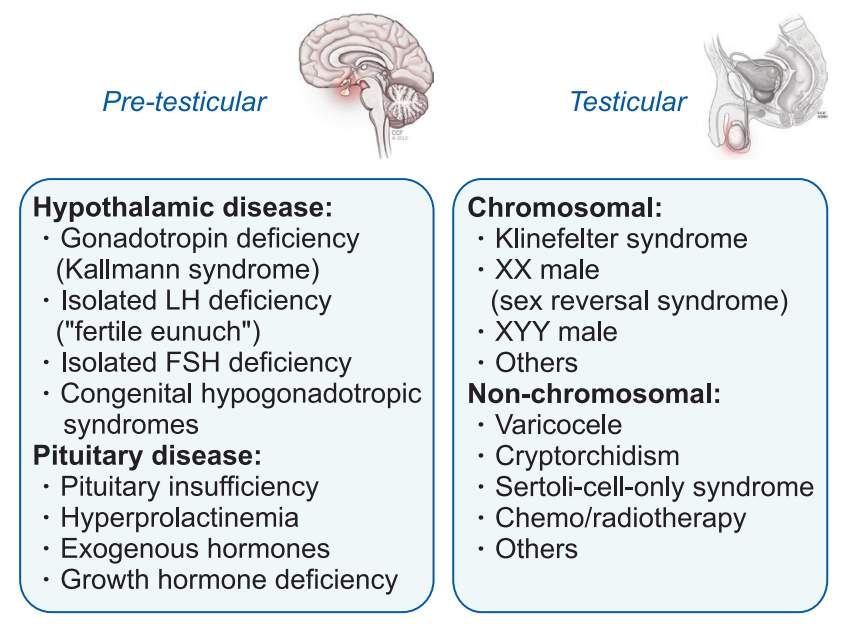

Fullness of the epididymis may indicate obstruction, while an underdeveloped epididymal tail together with unilateral or bilateral absence of the vas deference is seen in cystic fibrosis patients or carriers. In addition, hard swelling of the epididymal tail and beading of the vas deference can occur as a sequela of granulomatous inflammation secondary to tuberculosis infection. The cord is then examined for a varicocele which is clinically classified into three grades [22]. Grade 1: varicocele palpation is only demonstrated through valsalva maneuver; grade 2: palpation is felt regardless of valsalva maneuver; and grade 3: varicocele is visible without palpation.

Digital rectal examination is usually indicated in patients with low ejaculate volume, or above 50 years of age with lower urinary tract symptoms. The prostate is assessed for size and consistency while palpation of the seminal vesicles may indicate ejaculatory duct obstruction or a seminal vesicle pathology. A comprehensive initial assessment is a key component of the male fertility workup, it may indicate underlying causes of infertility, but also factors that could pose a significant risk to overall male health and potential progeny conceived naturally or with ART [23].

\section{MALE INFERTILITY: INVESTIGATIONS}

A number of laboratory and radiologic investigations are available for the evaluation of male infertility. Their respective indications are presented in Fig. 6. Semen analysis is the single most important investigation during the evaluation of infertile men. Despite its value as the cornerstone test of a man's fertility potential, it fails as a true predictor of fecundity [24]. To ensure

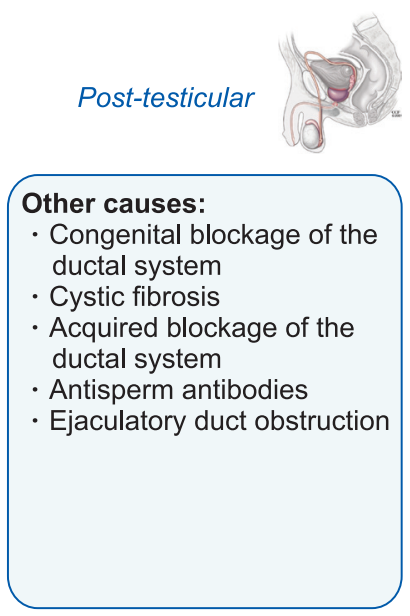

Fig. 5. Causes of male infertility. LH: luteinizing hormone, FSH: follicle-stimulating hormone. 


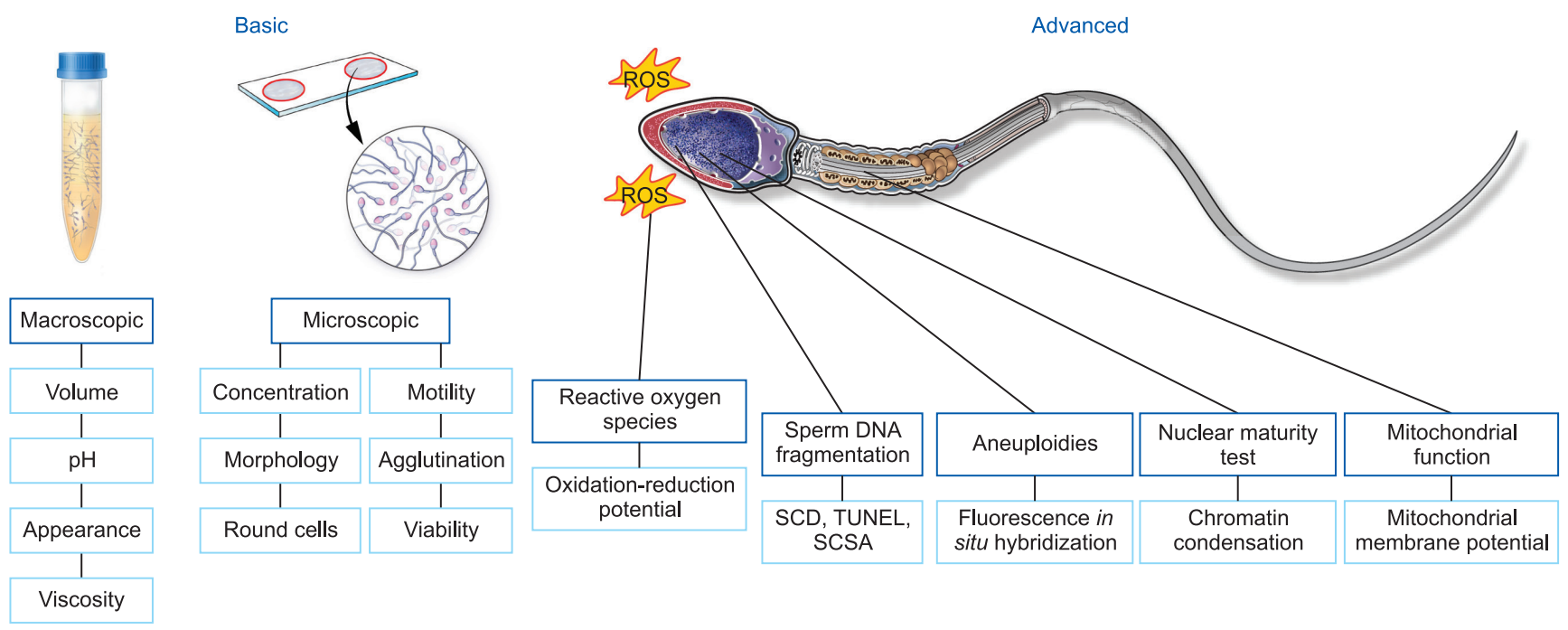

Fig. 6. Laboratory evaluation for male infertility. ROS: reactive oxygen species, SCD: sperm chromatin dispersion test, TUNEL: transferase-mediated dUTP nick end labeling, SCSA: sperm chromatin structure assay.

accurate and homogeneous results, samples are better analyzed at laboratories implementing quality control programs for semen analysis and adopting the latest World Health Organization protocols for semen testing and reporting of reference values [25]. The shortcoming of conventional semen analysis to accurately predict fecundity triggered the search for advanced tests of sperm function. While several tests have been explored, measurement of seminal oxidative stress and levels of sperm DNA fragmentation (SDF) are currently the most commonly utilized.

\section{Oxidative stress}

Reactive oxygen species (ROS) are highly reactive, oxygen containing molecules that, at physiologic levels, augment key steps, such as sperm capacitation and maturation necessary for optimal function [26,27]. Nevertheless, unphysiologically elevated amounts of ROS can have an opposite effect impairing and damaging the function of several enzymes and inducing lipid peroxidation and SDF [28,29]. Antioxidants, on the other hand, through their ability to neutralize or scavenge excessive ROS help in maintaining a natural redox balance [30]. However, when this balance is disrupted due to excessive production of ROS or reduced quantities of antioxidants, a state of oxidative stress will ensue (Fig. 7). Studies have confirmed the impact of oxidative stress on male fertility through finding significantly higher levels of ROS in semen samples obtained from infertile patients compared with fertile men [28,31,32].
Several direct and indirect measures of oxidative stress are available. The chemiluminescence assay which directly measures the interaction between ROS and certain reagents is the most commonly utilized method for oxidative stress measurement [33]. The thiobarbituric acid assay is an example of indirect tests for oxidative stress, which measures the levels of malondialdehyde, a byproduct of lipid peroxidation [34]. Recently, measurement of the oxidation-reduction potential with MiOXSYS (Male Infertility Oxidative Stress System) has been introduced, which directly assesses the balance between oxidants and reductants in seminal fluid [28,35]. The advantages of oxidative stress testing are perhaps more pronounced in men with idiopathic infertility as the test result can direct treatment decisions [36]. Examples of treatments that can be offered include the application of risk reduction strategies, treatment of genital tract infections or varicocele and the monitored use of oral antioxidants.

\section{Sperm DNA fragmentation}

Sperm DNA structure is unique, as the DNA is bound to protamines allowing it to be present in a compact, array-type state and shielding it from potential damage occurring during sperm transport [37]. However, sperm DNA damage may still occur due to errors in chromatin condensation or excessive ROS levels thereby affecting fertility potential [38]. In addition, since the enzyme topoisomerase II is cleaving DNA strands during the process of sperm chromatin conden- 

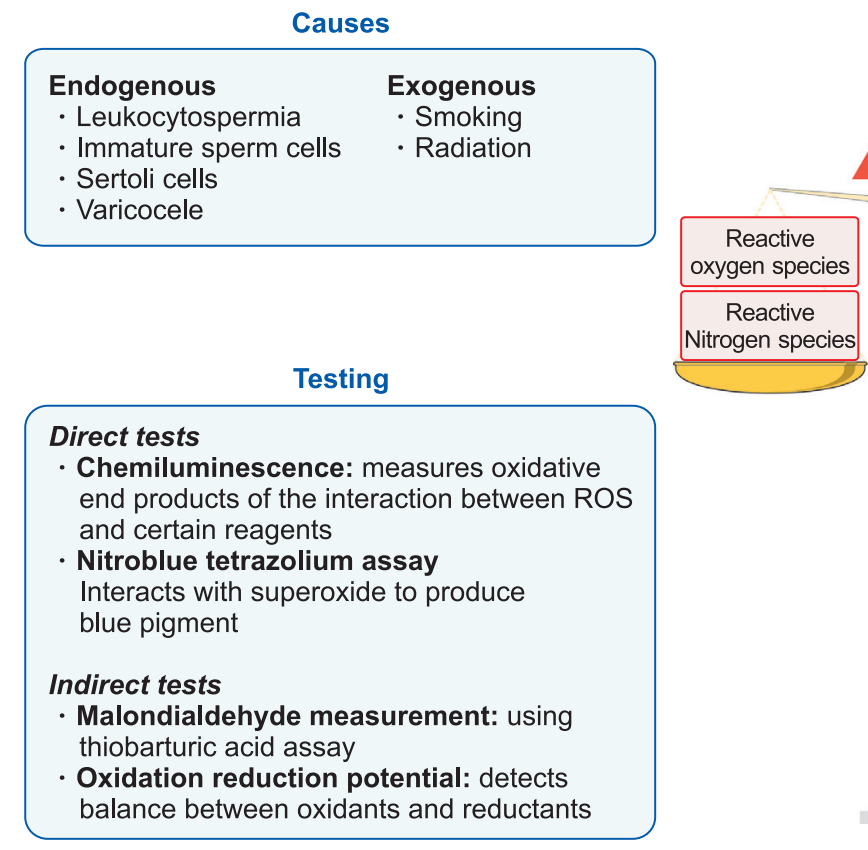

Direct tests

Chemiluminescence: measures oxidative

end products of the interaction between ROS

and certain reagents

Interacts with superoxide to produce

blue pigmen

ndirect tests

Malondialdehyde measurement: using

Oxidation reduction potential: detects

balance between oxidants and reductants

Fig. 7. Oxidative stress. ROS: reactive oxygen species.

sation with the replacement of histones by protamines as nuclear proteins in order to achieve higher compaction, this opening of the DNA structure also makes the DNA more susceptible to damage through oxidative assaults. Apart from that, linking up these nicks, also by topoisomerase II, is also not been done in a $100 \%$ correct manner. Consequently, DNA strand breakages might occur leaving open nicks behind. Sperm with fragmented DNA can significantly impair fertilization, early embryo development, implantation, overall pregnancy rates and can even be the cause of early childhood cancer, particularly in male offspring [39].

Several methods for testing SDF have been identified with the four most commonly used tests being the terminal deoxynucleotidyl transferase-mediated dUTP nick end labeling, single cell gel electrophoresis, sperm chromatin dispersion test and sperm chromatin structure assay (Fig. 8) [40].

Recent guidelines have been published highlighting the clinical indications of SDF testing [41]. Unexplained infertility, recurrent spontaneous abortion, varicocele, recurrent ART failure and lifestyle risk factors have been linked with higher SDF levels [42]. Several treatment options are available for patients with high levels of SDF. These include risk reduction, frequent ejaculations [43], treatment with antioxidants [44], varicocele ligation [45] and the use of sperm selection techniques and/or testicular sperm for intracytoplasmic sperm in- jection (ICSI) [46,47].

New generation diagnostic modalities are emerging such as the proteomic, genomic and metabolomic analyses of sperm and seminal fluid and may hold the key to more accurate diagnosis and treatment of male infertility (Fig. 9). Proteins are essential cell signaling biomolecules and since spermatozoa are translationally and transcriptionally silent, they depend on seminal plasma proteins to function appropriately. Aberrant expression of proteins has been identified in seminal fluid of infertile men and several studies are underway aiming to explore these proteins in various etiologies of male infertility [48]. Metabolomic profiling of human spermatozoa identified a number of metabolites that were deranged in men with asthenozoospermia and may serve as potential target for further investigations [49]. Higher resolution assessment of genetic material using fluorescent in situ hybridization and microarray technologies hold great promise for accurately identifying relevant genetic biomarkers. Copy number variations, single nucleotide polymorphisms, and ribonucleic acids are examples of promising biomarkers that may be evaluated in the near future [50].

\section{AZOOSPERMIA}

Azoospermia, defined by the absence of sperm in the ejaculate, is a not uncommon presentation occurring 


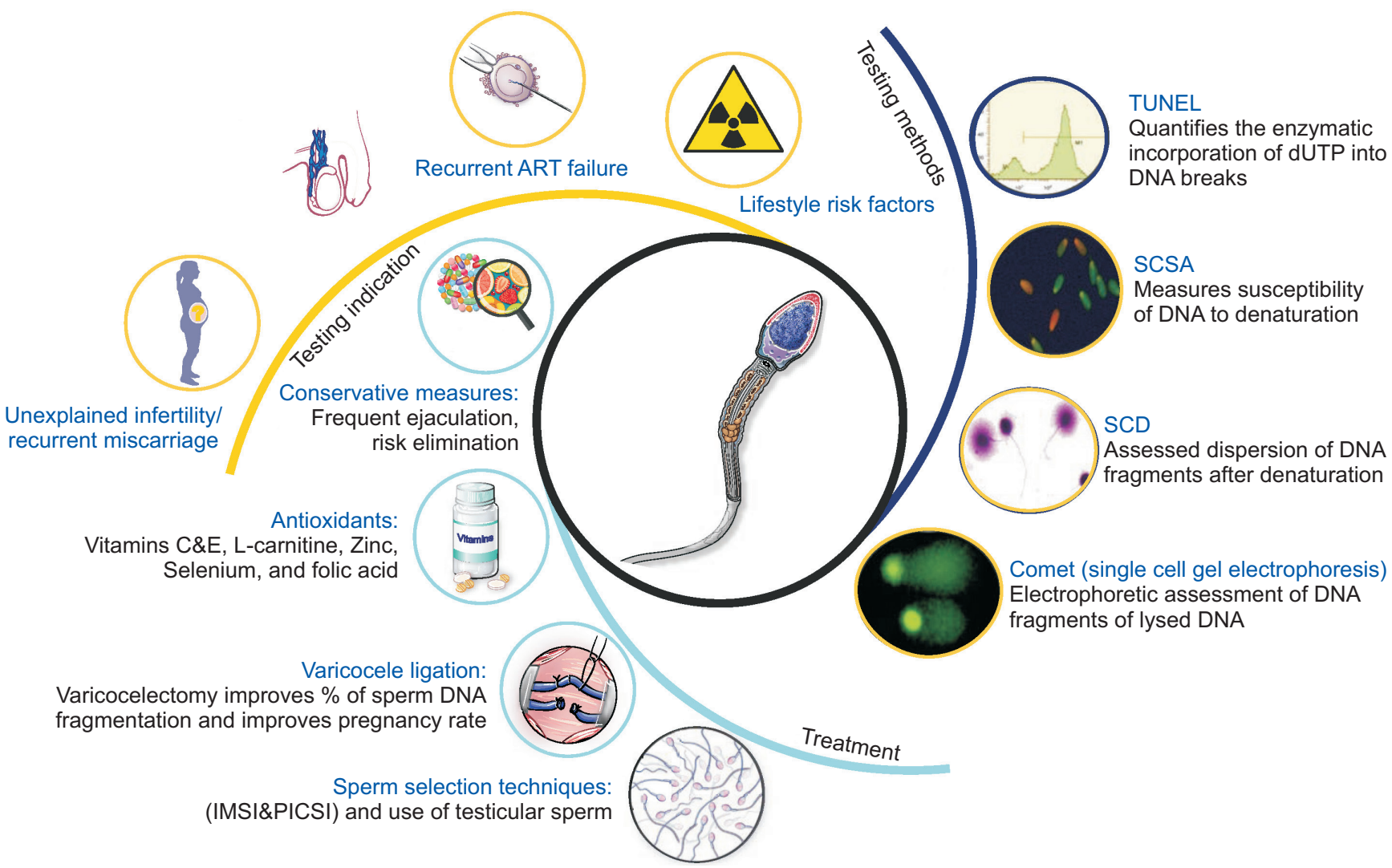

Fig. 8. Sperm DNA fragmentation. ART: assisted reproductive technology, IMSI: intracytoplasmic morphologically selected sperm injection, PICSI: physiological intracytoplasmic sperm injection, TUNEL: transferase-mediated dUTP nick end labeling, SCSA: sperm chromatin structure assay, SCD: sperm chromatin dispersion test.
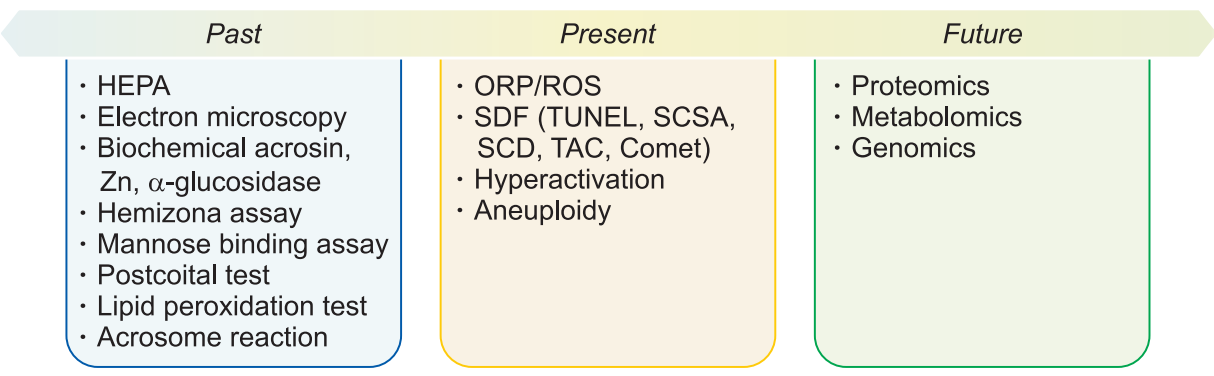

Fig. 9. Past, present, and future sperm function tests. HEPA: hamster egg penetration assay, ORP: oxidation reduction potential, ROS: reactive oxygen species, SDF: sperm DNA fragmentation, TUNEL: transferase-mediated dUTP nick end labeling, SCSA: sperm chromatin structure assay, SCD: sperm chromatin dispersion test, TAC: total antioxidant capacity, Comet: single cell gel electrophoresis.

in up to $15 \%$ of men consulting for infertility [51]. Vital information picked up during the history, physical examination and laboratory assessment may point out whether the azoospermia is of obstructive or non-obstructive nature (Fig. 10). Classically speaking, obstruction is generally suspected in patients with normal testicular size, full epididymides and normal hormone evaluation. While non-obstructive azoospermia (NOA) is assumed in patients with small testicular size, flat epididymides, and deranged hormonal assessment. Testicular biopsy can accurately discriminate these two conditions, however, it is rarely performed for diagnostic purposes solely due to its invasive nature and likelihood for negatively affecting the outcome of a possible forthcoming sperm retrieval procedure [52].

The AUA and ASRM recommends that in men with NOA or severe oligospermia $(<5$ million sperm $/ \mathrm{mL}$ ) karyotype and genetic evaluation should be considered 


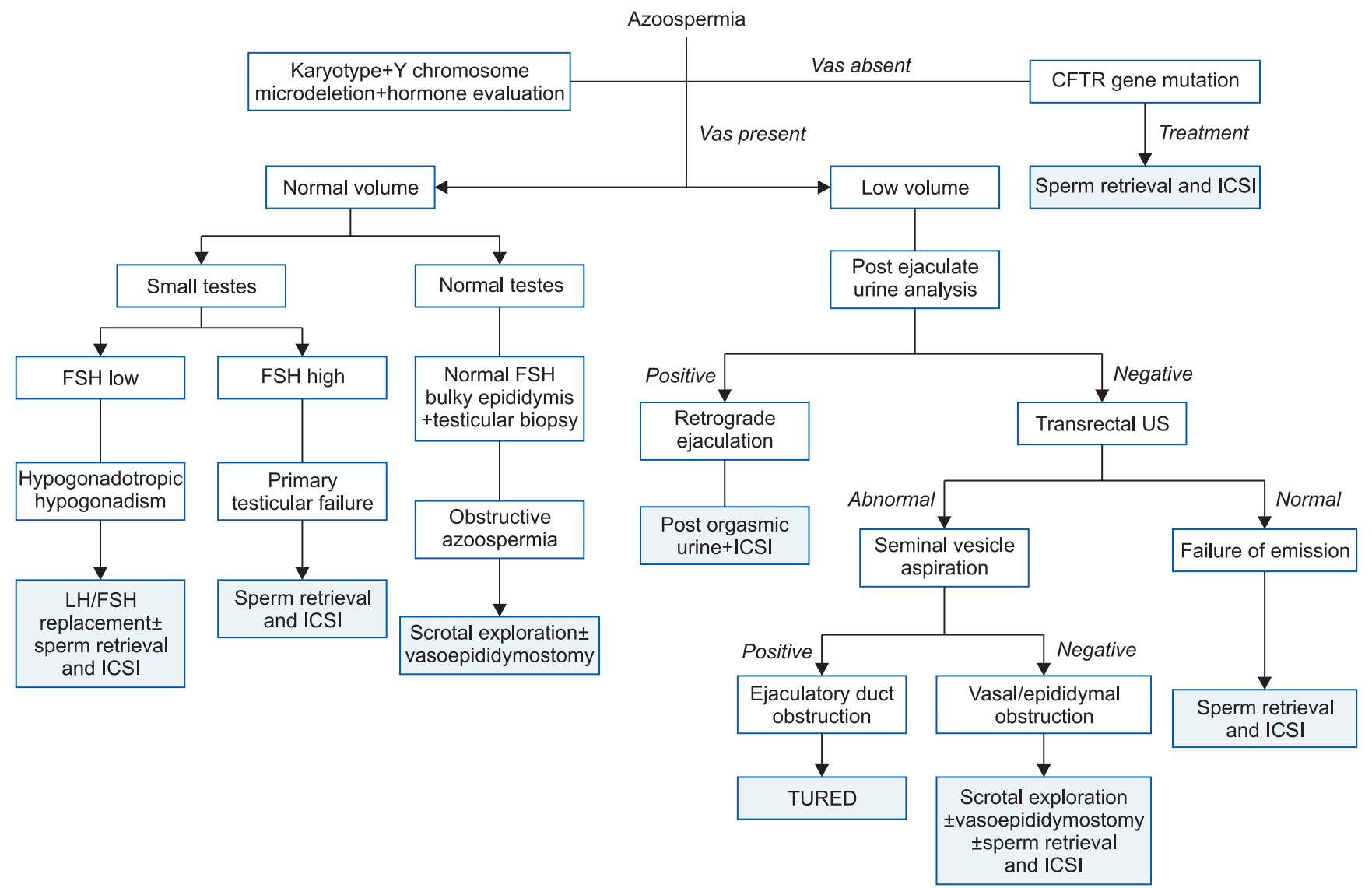

Fig. 10. Azoospermia. CFTR: cystic fibrosis transmembrane conductance regulator, ICSI: intracytoplasmic sperm injection, FSH: follicle-stimulating hormone, LH: luteinizing hormone, US: urethrography, TURED: transurethral resection of ejaculatory ducts.

$[12,13]$. The hormonal and genetic evaluation of patients with NOA will provide important information that would direct patient preparation for sperm retrieval procedures. Patients with hypogonadotropic hypogonadism will often respond to hormone replacement with gonadotropins and may even witness the return of sperm to the ejaculate and avoid surgical sperm retrieval. On the other hand, the results of a genetic testing may offer important prognostic information before sperm retrieval is performed. Genetic abnormalities are prevalent in about $2 \%$ to $7 \%$ of men with infertility [53], and in up to $35 \%$ of men with azoospermia and severe oligozoospermia, thus, justifying genetic testing in this patient population [54].

Karyotype analysis detects a number of autosomal aberrations such as translocations (Robertsonian and reciprocal), inversions and sex chromosomal abnormalities. A supernumerary X chromosome, or otherwise known as Klinefelter's syndrome is the most common sex chromosome abnormality detected in men with azoospermia [55]. Microdeletions of the azoospermia factor
(AZF) region of the $\mathrm{Y}$ chromosome have been linked with defective spermatogenesis and hence should be tested in azoospermic patients [56]. Three non-overlapping regions of the $\mathrm{Y}$ chromosome are investigated; the AZFa, AZFb and AZFc. Fortunately, about 2/3rd of patients have their deletion in the AZFc region, which has a better prognosis, in terms of the surgical sperm retrieval rate than the other regions [57]. In fact, many specialists would not offer sperm retrieval to patients with $\mathrm{AZFa}, \mathrm{AZFb}$, or $\mathrm{AZFa} / \mathrm{b}$ microdeletions due to a high failure rate [58,59]; although recent studies have reported sperm recovery from a few cases [60]. Patients with chromosomal abnormalities will also require genetic counselling and the use of pre-implantation genetic sampling after successful sperm recovery and fertilization.

Surgical sperm retrieval is a vital male infertility treatment milestone that significantly impacted the lives of many men who were previously considered sterile. Sperm retrieval was first performed in 1985 from epididymides of patients with obstructive 
azoospermia [61]. A decade later, Devroey et al [62], showed that sperm can also be retrieved from men with testicular failure and could be used for ICSI. Several refinements were introduced into the sperm retrieval procedure, the most prominent of which is the use of surgical microscopy [63]. Currently, sperm can be retrieved percutaneously (testicular sperm aspiration), conventionally (open testicular sperm extraction, TESE) or through microsurgery (micro TESE). The available evidence favors micro TESE as the "gold standard" approach as it is provides the highest sperm retrieval rate and the lowest risk of postoperative complications (Fig. 11) [64]. Studies have shown that in patients opting for sperm retrieval, pre-treatment with hormonal therapies can positively affect the surgical sperm retrieval outcome. Examples of medications used include antiestrogens [65], aromatase inhibitors [66] and gonadotropins [67].

Patients with obstructive azoospermia, whether it is iatrogenic (e.g., post vasectomy) or from prior infectious or traumatic etiologies can be offered reconstructive surgery or sperm retrieval procedures and ICSI (Fig. $12,13)$. Sperm retrieval generally has a high success rate and can be performed percutaneously from the epididymis (percutaneous epididymal sperm aspiration) or with the help of a surgical microscope (microsurgical epididymal sperm aspiration, MESA). While MESA offers some advantages over the percutaneous approach, it is time consuming, more expensive and requires superior surgical skills (Fig. 13) [68]. When epididymal sperm retrieval has failed, testicular sperm retrieval can also be conducted for obstructive azoospermia patients.

The macroscopic characteristics of the seminal fluid can also aid in diagnosing obstructive azoospermia where patients with a low semen volume, acidic $\mathrm{pH}$ and absence of fructose are considered to have ejaculatory duct obstruction. In these patients, a confirmatory post ejaculate urine analysis should be performed to rule out the presence of retrograde ejaculation, which is suspected in patients with a medical history suggesting neurologic impairment (diabetes mellitus or spinal/

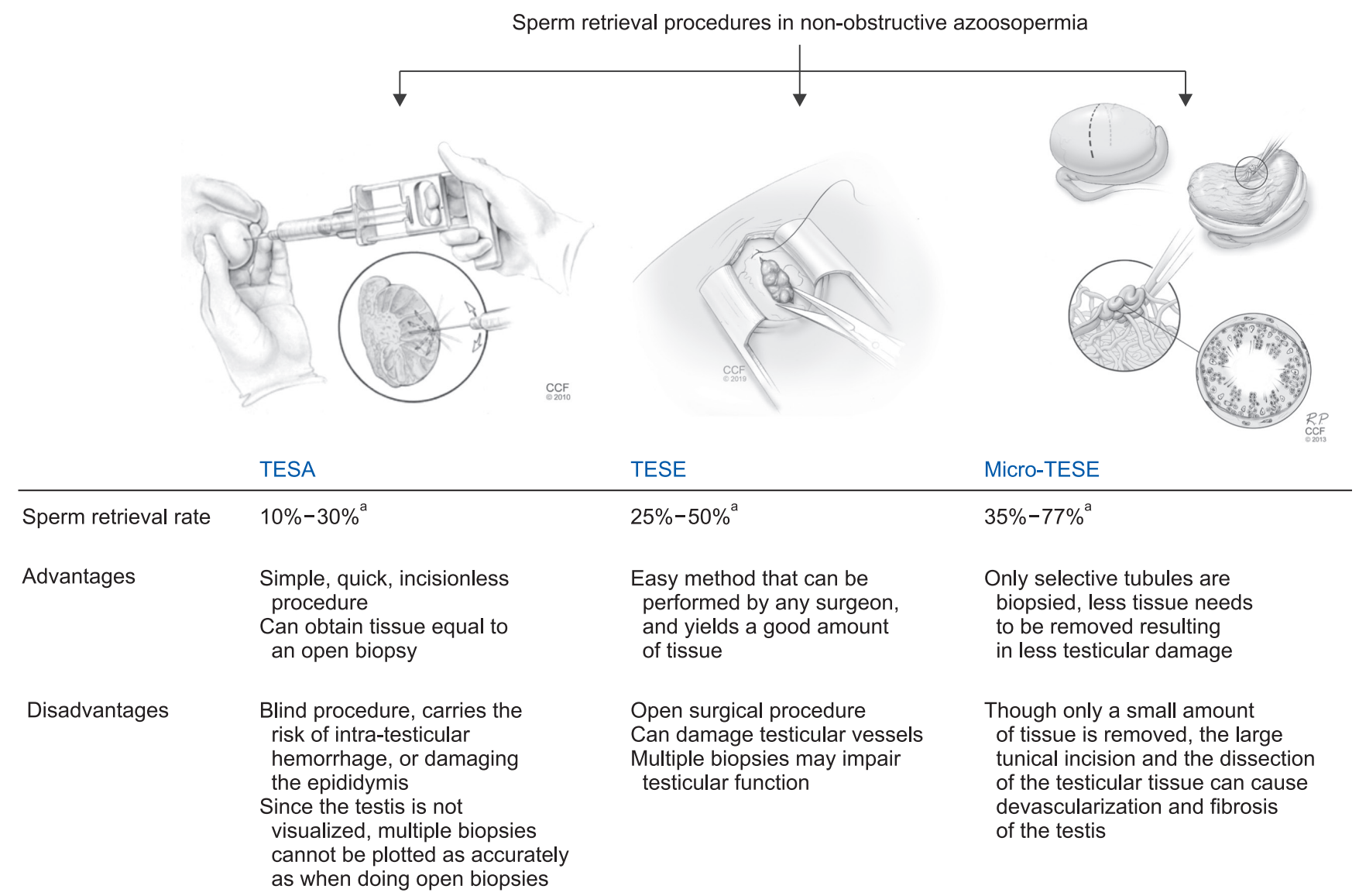

Fig. 11. Sperm retrieval procedures in non-obstructive azoospermia. TESA: testicular sperm aspiration, TESE: testicular sperm extraction. ${ }^{a}$ Data from the article of Donoso et al (Hum Reprod Update 2007;13:539-49) [64]. 


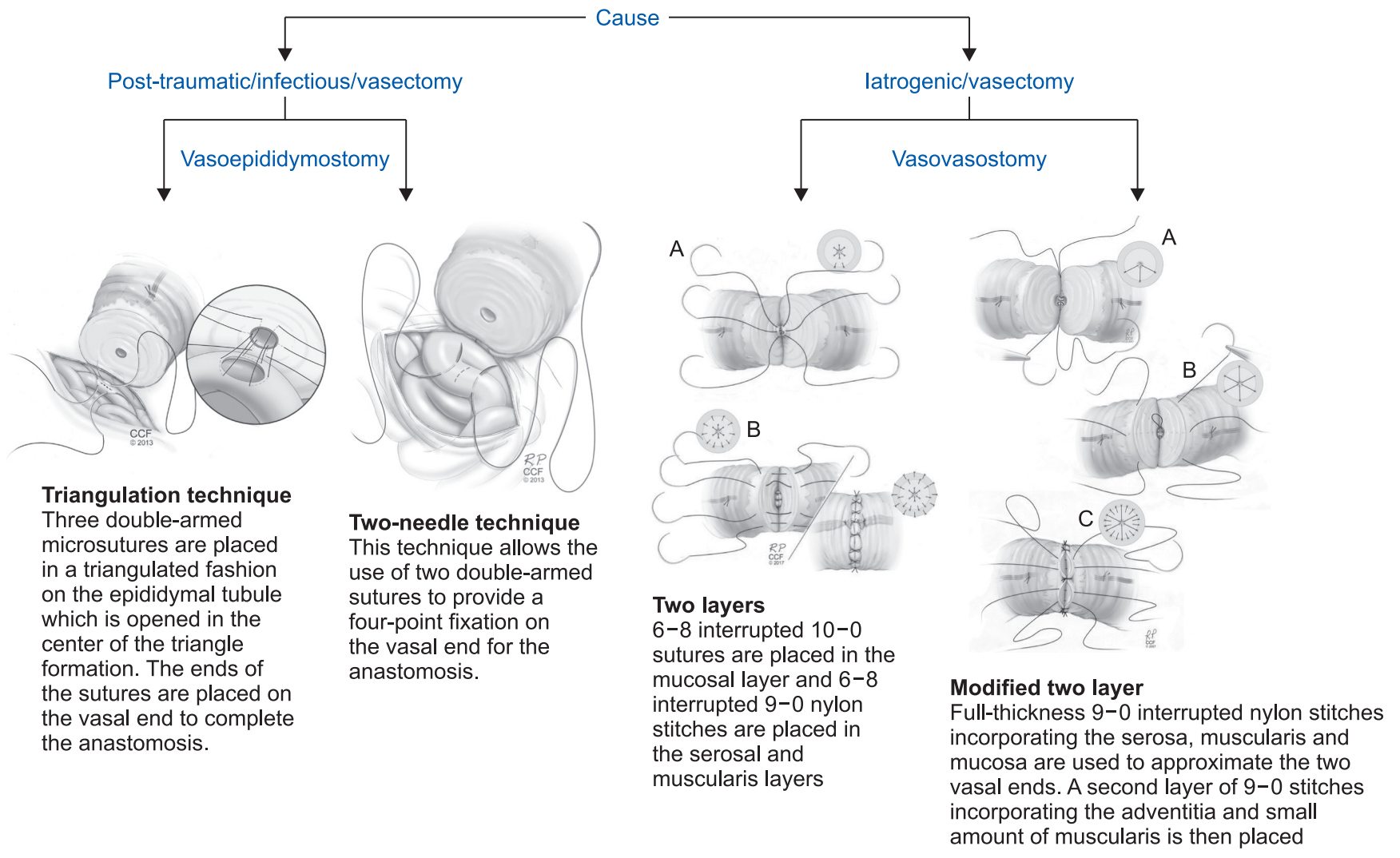

Fig. 12. Surgical correction of obstructive azoospermia.

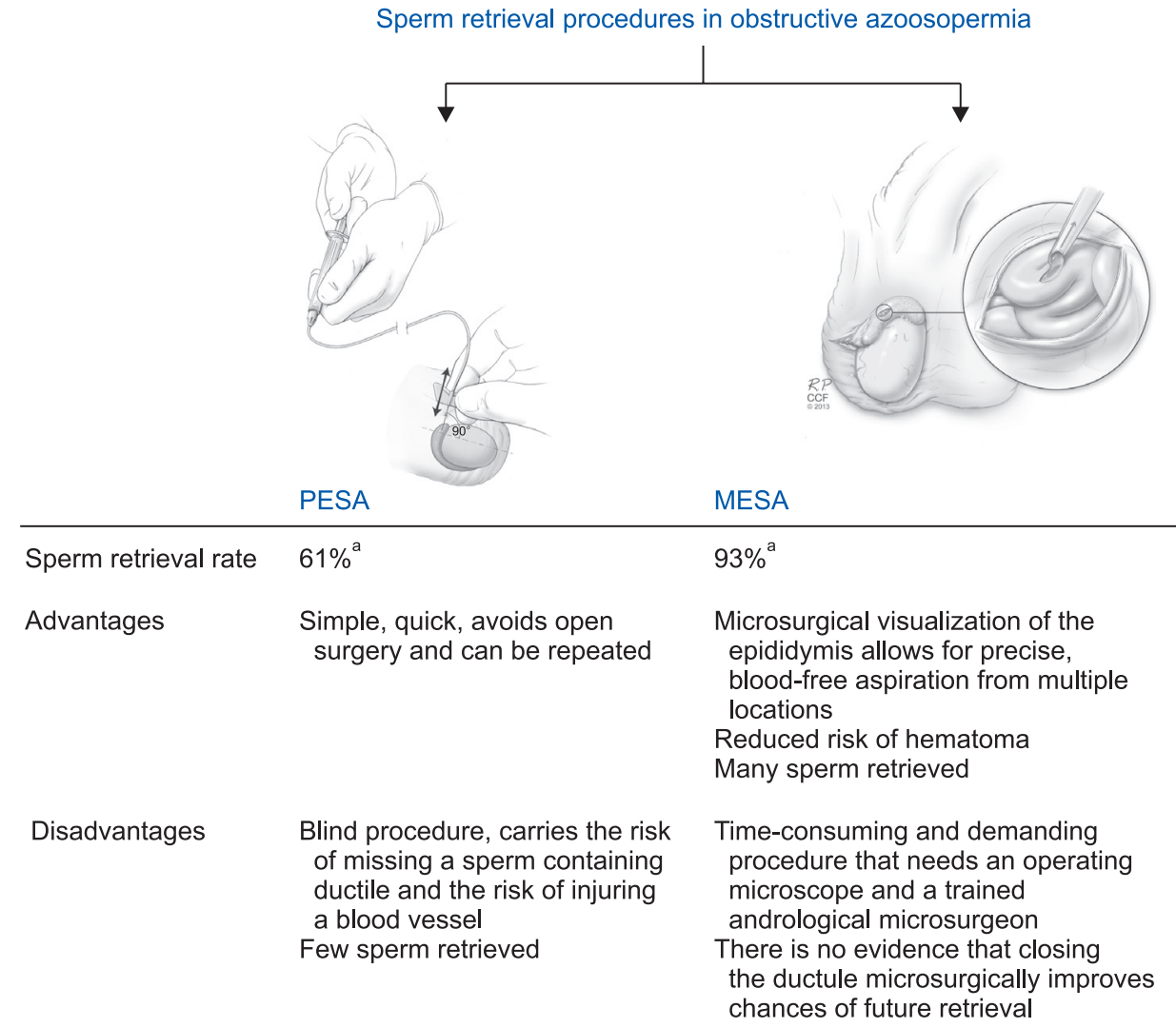

Fig. 13. Sperm retrieval procedures in obstructive azoospermia. PESA: percutaneous epididymal sperm aspiration, MESA: microsurgical epididymal sperm aspiration. ${ }^{\text {DD }}$ ata from the article of Esteves et al (J Urol 2013;189:232-7) [68]. 
pelvic surgery) [69]. A transrectal ultrasound is then performed to evaluate the prostate and seminal vesicles. Complete or partial ejaculatory duct obstruction is suspected in the presence of dilated seminal vesicles (>1.5 cm in diameter), dilated ejaculatory ducts ( $>2 \mathrm{~mm}$ in diameter) and/or midline prostatic cystic structures.

In order to improve the diagnostic accuracy of transrectal ultrasound in cases of ejaculatory duct obstruction, seminal vesicle aspiration and seminal vesiculography can be performed during the procedure.

Jarow [70] was the first to recognize that sperm are not normally present within the seminal vesicles and that ejaculatory duct obstruction should be suspected when three motile sperm per high-power field are detected in the seminal vesicle aspirate immediately after ejaculation. Patients with ejaculatory duct obstruction are offered transurethral resection of ejaculatory ducts which should improve sperm quality in $70 \%$ to $80 \%$ of patients with a $20 \%$ to $30 \%$ pregnancy rate [71]. Complications occur in $10 \%$ of cases and include hematuria, watery ejaculate, and epididymitis [71].

\section{VARICOCELE}

Varicocele, defined as the dilatation of the pampiniform plexus of veins together with reflux of blood, is a common etiology of male factor infertility. Much controversy surrounds this clinical condition mainly because it is also seen in patients with normal fertility potential. All efforts were directed towards selecting the ideal patient who would benefit from surgical ligation. Varicocele can affect testicular function through a number of mechanisms, the most commonly accepted include hyperthermia and testicular tissue hypoxia or ischemia (Fig. 14) [72]. This results in alteration in conventional semen parameters and sperm function tests (oxidative stress and SDF) [73].

The most accepted approach for varicocele treatment is surgical repair, whereas percutaneous embolization of the refluxing internal spermatic veins remains a primary alternative [74]. Varicocelectomy can be performed through the conventional retroperitoneal, laparoscopic/robotic or microsurgical inguinal or subinguinal approaches [75]. No major differences exist between the different surgical approaches with regards to success rate, however microsurgical subinguinal varicocelectomy has been considered the "gold standard" approach as it is associated with lower risk of varicocele recurrence and lower rate of postoperative hydrocele formation [76]. Varicocele ligation was found to improve conventional semen parameters and revert seminal oxidative stress and SDF [76].

Varicocele treatment has been recently indicated in patients with hypogonadism, regardless of semen parameter results as evidence have linked varicocele to Leydig cell hyperplasia and altered endocrine testicular function [77]. Furthermore, significant improvement in serum testosterone levels were observed following varicocelectomy $[78,79]$. Interest in varicocele ligation for patients with clinically palpable disease and non-

Pathophysiologic mechanisms

- Testicular hyperthermia

- Testicular hypoxia/ischemia

- Reflux of adrenal metabolites

- Oxidative stress

Varicocele ligation

- No difference between various repair

techniques on reproductive outcome

- Significantly lower complication rate with

microsurgical subinguinal varicocelectomy

(varicocele recurrence: $1 \%-2 \%$; hydrocele

formation: $<1 \%$ )

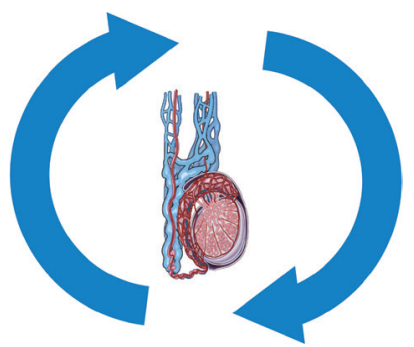

Facts/epidemiology

- $20 \%$ of general male population

- $40 \%$ of patients with primary infertility

- $80 \%$ of patients with secondary infertility

- Alters conventional semen parameters

- Alters sperm DNA fragmentation

- Alters endocrine status

Treatment outcome

- $60 \%-80 \%$ improvement in semen parameters

- 40\%-60\% improvement in pregnancy rate

- Improvement in sperm DNA fragmentation

- Improvement in serum testosterone levels

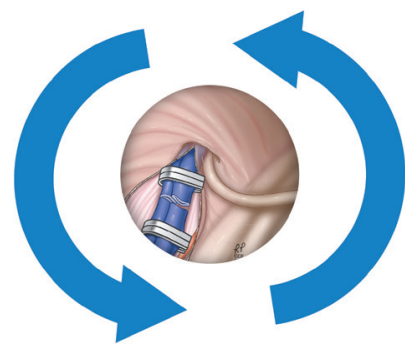

Fig. 14. Varicocele. 
obstructive azoospermia has re-emerged since the initial report by Tulloch [80] in 1952. Current evidence justifies varicocele ligation in this subset of patients as a good number of them will witness the return of sperm to the ejaculate thereby avoiding testicular sperm retrieval [81]. Moreover, those who remain azoospermic following varicocele ligation will also have a better surgical sperm retrieval outcome [81].

\section{CONCLUSIONS}

The field of male infertility has witnessed several advancements in the past few decades. These advancements were the result of the continued recognition of the key role that the male counterpart plays in human fecundity. With continued improvement in biotechnology, new generation tests of sperm function are underway to help understand the various pathophysiologies of testicular dysfunction. This should further allow the introduction of novel cause directed treatment modalities capable of restoring fertility potential.

\section{ACKNOWLEDGEMENTS}

This research was supported by the American Center for Reproductive Medicine.

The authors thank Joseph Terry from the Center for Medical Art and Photography for assistance with the figures.

\section{Conflict of Interest}

The authors have nothing to disclose.

\section{Author Contribution}

Conceptualization: AA. Data curation: all authors. Methodology: all authors. Resources: American Center for Reproductive Medicine, Cleveland Clinic. Writing-original draft: all authors. Writing-review \& editing: all authors.

\section{REFERENCES}

1. Steptoe PC, Edwards RG. Birth after the reimplantation of a human embryo. Lancet 1978;2:366.

2. Nangia AK, Likosky DS, Wang D. Distribution of male infertility specialists in relation to the male population and assisted reproductive technology centers in the United States.
Fertil Steril 2010;94:599-609.

3. Leung AK, Henry MA, Mehta A. Gaps in male infertility health services research. Transl Androl Urol 2018;7(Suppl 3): S303-9.

4. Mehta A, Nangia AK, Dupree JM, Smith JF. Limitations and barriers in access to care for male factor infertility. Fertil Steril 2016;105:1128-37.

5. Grey BR, O’Flynn KJ, Payne SR. UK urology trainees' exposure to dedicated infertility training: How good is that training? Br J Med Surg Urol 2012;5:34-8.

6. Krausz C, Brannigan RE, Sigman M. Subspecialty training in andrology. Fertil Steril 2015;104:12-5.

7. Boivin J, Bunting L, Collins JA, Nygren KG. International estimates of infertility prevalence and treatment-seeking: potential need and demand for infertility medical care. Hum Reprod 2007;22:1506-12.

8. Mascarenhas MN, Flaxman SR, Boerma T, Vanderpoel S, Stevens GA. National, regional, and global trends in infertility prevalence since 1990: a systematic analysis of 277 health surveys. PLoS Med 2012;9:e1001356.

9. Akyuz A, Seven M, Sahiner G, Bilal B. Studying the effect of infertility on marital violence in Turkish women. Int J Fertil Steril 2013;6:286-93.

10. Tao P, Coates R, Maycock B. Investigating marital relationship in infertility: a systematic review of quantitative studies. J Reprod Infertil 2012;13:71-80.

11. Brugh VM 3rd, Lipshultz LI. Male factor infertility: evaluation and management. Med Clin North Am 2004;88:367-85.

12. Jarow J, Sigman M, Kolettis PN, Lipshultz LR, McClure RD, Nangia AK, et al. The optimal evaluation of the infertile male: AUA best practice statement. Linthicum: American Urological Association; 2011.

13. Practice Committee of the American Society for Reproductive Medicine. Diagnostic evaluation of the infertile male: a committee opinion. Fertil Steril 2015;103:e18-25.

14. Soares SR, Melo MA. Cigarette smoking and reproductive function. Curr Opin Obstet Gynecol 2008;20:281-91.

15. Katib A. Mechanisms linking obesity to male infertility. Cent European J Urol 2015;68:79-85.

16. Emanuele MA, Emanuele NV. Alcohol's effects on male reproduction. Alcohol Health Res World 1998;22:195-201.

17. Jamalan M, Ghaffari MA, Hoseinzadeh P, Hashemitabar M, Zeinali M. Human sperm quality and metal toxicants: protective effects of some flavonoids on male reproductive function. Int J Fertil Steril 2016;10:215-23.

18. Ash $\mathrm{P}$. The influence of radiation on fertility in man. Br J Radiol 1980;53:271-8.

19. Thonneau P, Bujan L, Multigner L, Mieusset R. Occupational 
heat exposure and male fertility: a review. Hum Reprod 1998; 13:2122-5.

20. Honig SC, Lipshultz LI, Jarow J. Significant medical pathology uncovered by a comprehensive male infertility evaluation. Fertil Steril 1994;62:1028-34.

21. Walsh TJ, Croughan MS, Schembri M, Chan JM, Turek PJ. Increased risk of testicular germ cell cancer among infertile men. Arch Intern Med 2009;169:351-6.

22. Dubin L, Amelar RD. Varicocele size and results of varicocelectomy in selected subfertile men with varicocele. Fertil Steril 1970;21:606-9.

23. Kolettis PN, Sabanegh ES. Significant medical pathology discovered during a male infertility evaluation. J Urol 2001;166: 178-80.

24. Guzick DS, Overstreet JW, Factor-Litvak P, Brazil CK, Nakajima ST, Coutifaris C, et al.; National Cooperative Reproductive Medicine Network. Sperm morphology, motility, and concentration in fertile and infertile men. N Engl J Med 2001; 345:1388-93.

25. Cooper TG, Noonan E, von Eckardstein S, Auger J, Baker HW, Behre HM, et al. World Health Organization reference values for human semen characteristics. Hum Reprod Update 2010;16:231-45.

26. Sharma RK, Agarwal A. Role of reactive oxygen species in male infertility. Urology 1996;48:835-50.

27. Rivlin J, Mendel J, Rubinstein S, Etkovitz N, Breitbart H. Role of hydrogen peroxide in sperm capacitation and acrosome reaction. Biol Reprod 2004;70:518-22.

28. Majzoub A, Arafa M, Mahdi M, Agarwal A, Al Said S, AlEmadi I, et al. Oxidation-reduction potential and sperm DNA fragmentation, and their associations with sperm morphological anomalies amongst fertile and infertile men. Arab J Urol 2018;16:87-95.

29. Agarwal A, Makker K, Sharma R. Clinical relevance of oxidative stress in male factor infertility: an update. Am J Reprod Immunol 2008;59:2-11.

30. Agarwal A, Gupta S, Sikka S. The role of free radicals and antioxidants in reproduction. Curr Opin Obstet Gynecol 2006; 18:325-32.

31. Turner TT, Lysiak JJ. Oxidative stress: a common factor in testicular dysfunction. J Androl 2008;29:488-98.

32. Tremellen K. Oxidative stress and male infertility--a clinical perspective. Hum Reprod Update 2008;14:243-58.

33. Agarwal A, Allamaneni SS, Said TM. Chemiluminescence technique for measuring reactive oxygen species. Reprod Biomed Online 2004;9:466-8.

34. Shang XJ, Li K, Ye ZQ, Chen YG, Yu X, Huang YF. Analysis of lipid peroxidative levels in seminal plasma of infertile men by high-performance liquid chromatography. Arch Androl 2004; 50:411-6.

35. Agarwal A, Sharma R, Roychoudhury S, Du Plessis S, Sabanegh E. MiOXSYS: a novel method of measuring oxidation reduction potential in semen and seminal plasma. Fertil Steril 2016;106:566-73.e10.

36. Agarwal A, Sekhon LH. Oxidative stress and antioxidants for idiopathic oligoasthenoteratospermia: Is it justified? Indian J Urol 2011;27:74-85.

37. Erenpreiss J, Spano M, Erenpreisa J, Bungum M, Giwercman A. Sperm chromatin structure and male fertility: biological and clinical aspects. Asian J Androl 2006;8:11-29.

38. Evenson DP, Jost LK, Marshall D, Zinaman MJ, Clegg E, Purvis $\mathrm{K}$, et al. Utility of the sperm chromatin structure assay as a diagnostic and prognostic tool in the human fertility clinic. Hum Reprod 1999;14:1039-49.

39. Lewis SE, John Aitken R, Conner SJ, Iuliis GD, Evenson DP, Henkel R, et al. The impact of sperm DNA damage in assisted conception and beyond: recent advances in diagnosis and treatment. Reprod Biomed Online 2013;27:325-37.

40. Majzoub A, Agarwal A, Cho CL, Esteves SC. Sperm DNA fragmentation testing: a cross sectional survey on current practices of fertility specialists. Transl Androl Urol 2017; 6(Suppl 4):S710-9.

41. Agarwal A, Cho CL, Majzoub A, Esteves SC. The Society for Translational Medicine: clinical practice guidelines for sperm DNA fragmentation testing in male infertility. Transl Androl Urol 2017;6(Suppl 4):S720-33.

42. Agarwal A, Majzoub A, Esteves SC, Ko E, Ramasamy R, Zini A. Clinical utility of sperm DNA fragmentation testing: practice recommendations based on clinical scenarios. Transl Androl Urol 2016;5:935-50.

43. Mayorga-Torres BJ, Camargo M, Agarwal A, du Plessis SS, Cadavid ÁP, Cardona Maya WD. Influence of ejaculation frequency on seminal parameters. Reprod Biol Endocrinol 2015; 13:47.

44. Majzoub A, Agarwal A, Esteves SC. Antioxidants for elevated sperm DNA fragmentation: a mini review. Transl Androl Urol 2017;6(Suppl 4):S649-53.

45. Ni K, Steger K, Yang H, Wang H, Hu K, Chen B. Sperm protamine mRNA ratio and DNA fragmentation index represent reliable clinical biomarkers for men with varicocele after microsurgical varicocele ligation. J Urol 2014;192:170-6.

46. Arafa M, AlMalki A, AlBadr M, Burjaq H, Majzoub A, AlSaid $S$, et al. ICSI outcome in patients with high DNA fragmentation: testicular versus ejaculated spermatozoa. Andrologia 2018;50:e12835.

47. Majzoub A, Agarwal A, Esteves SC. Sperm DNA fragmenta- 
tion for the evaluation of male infertility: clinical algorithms. Transl Androl Urol 2017;6(Suppl 4):S405-8.

48. Panner Selvam MK, Agarwal A. Update on the proteomics of male infertility: a systematic review. Arab J Urol 2017;16:10312.

49. Zhao K, Zhang J, Xu Z, Xu Y, Xu A, Chen W, et al. Metabolomic profiling of human spermatozoa in idiopathic asthenozoospermia patients using gas chromatography-mass spectrometry. Biomed Res Int 2018;2018:8327506.

50. Kovac JR, Pastuszak AW, Lamb DJ. The use of genomics, proteomics, and metabolomics in identifying biomarkers of male infertility. Fertil Steril 2013;99:998-1007.

51. Thonneau P, Marchand S, Tallec A, Ferial ML, Ducot B, Lansac J, et al. Incidence and main causes of infertility in a resident population $(1,850,000)$ of three French regions (1988-1989). Hum Reprod 1991;6:811-6.

52. Practice Committee of the American Society for Reproductive Medicine in collaboration with the Society for Male Reproduction and Urology. Evaluation of the azoospermic male: a committee opinion. Fertil Steril 2018;109:777-82.

53. Baschat AA, Küpker W, al Hasani S, Diedrich K, Schwinger E. Results of cytogenetic analysis in men with severe subfertility prior to intracytoplasmic sperm injection. Hum Reprod 1996; 11:330-3.

54. Pylyp LY, Spinenko LO, Verhoglyad NV, Zukin VD. Chromosomal abnormalities in patients with oligozoospermia and non-obstructive azoospermia. J Assist Reprod Genet 2013; 30:729-32.

55. Gekas J, Thepot F, Turleau C, Siffroi JP, Dadoune JP, Briault S, et al.; Association des Cytogeneticiens de Langue Francaise. Chromosomal factors of infertility in candidate couples for ICSI: an equal risk of constitutional aberrations in women and men. Hum Reprod 2001;16:82-90.

56. Vogt PH, Edelmann A, Kirsch S, Henegariu O, Hirschmann P, Kiesewetter F, et al. Human Y chromosome azoospermia factors (AZF) mapped to different subregions in Yq11. Hum Mol Genet 1996;5:933-43.

57. Foresta C, Moro E, Ferlin A. Y chromosome microdeletions and alterations of spermatogenesis. Endocr Rev 2001;22:22639.

58. Kamp C, Huellen K, Fernandes S, Sousa M, Schlegel PN, Mielnik A, et al. High deletion frequency of the complete AZFa sequence in men with Sertoli-cell-only syndrome. Mol Hum Reprod 2001;7:987-94.

59. Park SH, Lee HS, Choe JH, Lee JS, Seo JT. Success rate of microsurgical multiple testicular sperm extraction and sperm presence in the ejaculate in Korean men with y chromosome microdeletions. Korean J Urol 2013;54:536-40.
60. Goncalves C, Cunha M, Rocha E, Fernandes S, Silva J, Ferraz $\mathrm{L}$, et al. Y-chromosome microdeletions in nonobstructive azoospermia and severe oligozoospermia. Asian J Androl 2017;19:338-45.

61. Temple-Smith PD, Southwick GJ, Yates CA, Trounson AO, de Kretser DM. Human pregnancy by in vitro fertilization (IVF) using sperm aspirated from the epididymis. J In Vitro Fert Embryo Transf 1985;2:119-22.

62. Devroey P, Liu J, Nagy Z, Goossens A, Tournaye H, Camus M, et al. Pregnancies after testicular sperm extraction and intracytoplasmic sperm injection in non-obstructive azoospermia. Hum Reprod 1995;10:1457-60.

63. Silber SJ. Microsurgical TESE and the distribution of spermatogenesis in non-obstructive azoospermia. Hum Reprod 2000;15:2278-84.

64. Donoso P, Tournaye H, Devroey P. Which is the best sperm retrieval technique for non-obstructive azoospermia? A systematic review. Hum Reprod Update 2007;13:539-49.

65. Chua ME, Escusa KG, Luna S, Tapia LC, Dofitas B, Morales M. Revisiting oestrogen antagonists (clomiphene or tamoxifen) as medical empiric therapy for idiopathic male infertility: a meta-analysis. Andrology 2013;1:749-57.

66. Schlegel PN. Aromatase inhibitors for male infertility. Fertil Steril 2012;98:1359-62.

67. Shiraishi K, Ohmi C, Shimabukuro T, Matsuyama H. Human chorionic gonadotrophin treatment prior to microdissection testicular sperm extraction in non-obstructive azoospermia. Hum Reprod 2012;27:331-9.

68. Esteves SC, Lee W, Benjamin DJ, Seol B, Verza S Jr, et al. Reproductive potential of men with obstructive azoospermia undergoing percutaneous sperm retrieval and intracytoplasmic sperm injection according to the cause of obstruction. J Urol 2013;189:232-7.

69. Rowland D, McMahon CG, Abdo C, Chen J, Jannini E, Waldinger $\mathrm{MD}$, et al. Disorders of orgasm and ejaculation in men. J Sex Med 2010;7(4 Pt 2):1668-86.

70. Jarow JP. Seminal vesicle aspiration in the management of patients with ejaculatory duct obstruction. J Urol 1994;152:899901.

71. El-Assmy A, El-Tholoth H, Abouelkheir RT, Abou-El-Ghar ME. Transurethral resection of ejaculatory duct in infertile men: outcome and predictors of success. Int Urol Nephrol 2012;44:1623-30.

72. Naughton CK, Nangia AK, Agarwal A. Pathophysiology of varicoceles in male infertility. Hum Reprod Update 2001;7: 473-81.

73. Cho CL, Esteves SC, Agarwal A. Novel insights into the pathophysiology of varicocele and its association with reac- 
tive oxygen species and sperm DNA fragmentation. Asian J Androl 2016;18:186-93.

74. Shridharani A, Owen RC, Elkelany OO, Kim ED. The significance of clinical practice guidelines on adult varicocele detection and management. Asian J Androl 2016;18:269-75.

75. Rajfer J. Varicoceles: practice guidelines. Rev Urol 2007;9:161.

76. Practice Committee of the American Society for Reproductive Medicine; Society for Male Reproduction and Urology. Report on varicocele and infertility: a committee opinion. Fertil Steril 2014;102:1556-60.

77. Kadihasanoglu M, Ozbek E. Varicocele is associated with hypogonadism and impaired erectile function: a prospective comparative study. Andrologia 2017;49:e12785.

78. Sathya Srini V, Belur Veerachari S. Does varicocelectomy improve gonadal function in men with hypogonadism and infertility? Analysis of a prospective study. Int J Endocrinol 2011;2011:916380.

79. Zohdy W, Ghazi S, Arafa M. Impact of varicocelectomy on gonadal and erectile functions in men with hypogonadism and infertility. J Sex Med 2011;8:885-93.

80. Tulloch WS. A consideration of sterility factors in the light of subsequent pregnancies. II. Sub fertility in the male. (Tr. Edinburgh Obst. Soc. Session 104). Edinb Med J 1952;59:T2934.

81. Esteves SC, Miyaoka R, Roque M, Agarwal A. Outcome of varicocele repair in men with nonobstructive azoospermia: systematic review and meta-analysis. Asian J Androl 2016;18: 246-53. 